\title{
Perfil sociodemográfico, judicial e experiências na família de origem de homens que cumprem pena por estupro de vulnerável
}

\author{
Caroline Velasquez Marafiga \\ Denise Falcke
}

\begin{abstract}
Resumo: Pesquisas com vitimizadores sexuais infantis são escassas, especialmente em contexto nacional. Objetivou-se descrever o perfil sociodemográfico, judicial e as experiências na família de origem de homens condenados pelo crime de estupro de vulnerável. Trata-se de um estudo transversal descritivo, realizado com 49 homens em cumprimento de pena. Foi realizado levantamento documental dos processos judiciais e aplicação de questionário de dados sociodemográficos e judiciais, além do Family Background Questionnaire. Análises estatísticas descritivas e inferenciais revelaram predomínio de vitimizadores solteiros $(53,1 \%)$, mas com filhos $(82,2 \%)$. Somente $6,1 \%$ tinham diagnóstico de transtorno pedofílico. Os crimes ocorreram preponderantemente em contexto intrafamiliar (54,5\%) e com vítimas do sexo feminino (74,3\%). Mais de 30\% revelaram contato sexual indesejado ao longo da vida. Os vitimizadores de contextos extrafamiliares vivenciaram significativamente mais negligência na família de origem $(M=22,71)$ do que os intrafamiliares $(\mathrm{M}=14,66)$. Ressalta-se a necessidade de novos estudos para compreender com mais abrangência o perfil desta população.
\end{abstract}

Palavras-chave: Abuso sexual infantil, família de origem, estupro de vulnerável.

\section{Sociodemographic, judicial profile and experiences in the family of origin of men serving time for rape of the vulnerable}

\begin{abstract}
Research on sex offenders is scarce, especially in Brazil. This study aims to describe the socio-demographic and judicial profile of men convicted for statutory rape and their experiences in family of origin. It is a descriptive cross-sectional study performed with 49 men serving time. A documentary survey of their lawsuits was performed and the administration of a socio-demographic and judicial data questionnaire, as well as the Family Background Questionnaire. Descriptive and inferential statistical analyzes revealed a predominance of single victimizers $(53.1 \%)$, with children (82.2\%). Only $6.1 \%$ had a diagnosis of pedophilic disorder. The crimes occurred predominantly inside the family (54.5\%) and with female victims (74.3\%). More than $30 \%$ revealed unwanted sexual contacts throughout their lives. Extra familiar victimizers had significantly higher levels of neglect in their family of origin $(M=22.71)$ than intrafamiliar $(M=14.66)$. Further studies are necessary to understand the profile of this population more comprehensively.
\end{abstract}

Keywords: child sexual abuse, family-of-origin, statutory rape.

\section{Introdução}

A violência sexual contra crianças e adolescentes é um grave problema de saúde pública (Sanches, Araujo, Ramos, Rozin \& Rauli, 2019; Seto, Babchishin, Pullman \& McPhail, 2015). Devido à incidência e às sérias consequências para o desenvolvimento 
social, afetivo e cognitivo das vítimas e de suas famílias, a violência acarreta dano psicológico que pode perdurar por toda vida (Falcke, 2020; Silva, \& Gonçalves, 2019).

$\mathrm{Na}$ literatura, especialmente no contexto nacional, há um número expressivo de pesquisas sobre crianças vítimas de violência sexual infantil em relação ao pequeno número de publicações sobre vitimizadores (Scortegagna \& Amparo, 2013), ainda que, nos últimos anos, pesquisadores tenham evidenciado preocupação com esse assunto (Barros, 2017; Bertoli, Benato \& Machado, 2018; Casarin, Botelho \& Ribeiro, 2016; Sanches et al., 2019; Costa, Rocha \& Cavalcante, 2018; Marafiga, Falcke \& Teodoro, 2017; Platt, Back, Hauschild \& Guedert, 2018).

No contexto internacional, pode-se observar que as publicações envolvendo não somente vítimas, mas também vitimizadores sexuais infantis, abrangem um leque vasto, mesmo se tratando de uma temática bastante delicada (Seto et al., 2015; Vanderstukken, Benbouriche, Pham \& Lefebvre, 2015). Estudos internacionais (Dyshniku, Murray, Fazio, Lykins \& Cantor, 2015; Fazio, Lykins \& Cantor, 2014) enfatizam questões biológicas e respostas fisiológicas a demandas relacionadas à interação sexual entre crianças e/ou adolescentes com adultos. Pesquisa também apresenta estudo de caso único (Reyes, Ymas, Gonzalez \& Sanches, 2012), identificando questões relacionadas à história de vida e subjetividade no processo de vitimização sexual de crianças e/ou adolescentes.

Em menor número, porém mais recentes, encontram-se os estudos que buscam analisar características de personalidade de homens que apresentam interesses sexuais por crianças e/ou adolescentes (Chan, Beauregard \& Myers, 2015; Cohen et al., 2018), os que analisam as características de vitimizadores sexuais infantis em contexto intra e extrafamiliar (Costa et al., 2018) e os que analisam os esquemas iniciais desadaptativos de indivíduos apenados por crimes sexuais contra crianças (Henriques, 2016; Vanderstukken et al., 2015). Pesquisas relacionadas às experiências de violência na família de origem de indivíduos condenados por crimes sexuais contra crianças e/ou adolescentes são escassas, mesmo que diversos autores afirmem que crescer em uma família de origem violenta, negligente e estressante são fatores determinantes na perpetuação da violência em uma perspectiva transgeracional (Azevedo, Alves \& Tavares, 2018; Falcke, 2020; PournaghashTehrani, \& Feizabadi, 2009). O estudo de Titcomb, Goodman-Delahunty e Puiseau (2012) descreve experiências de vitimização física, emocional ou sexual por quase metade dos 112 autores de agressão sexual contra crianças e/ou adolescentes da amostra, sendo que $43,8 \%$ revelaram terem sido vítimas de abuso físico ou emocional antes dos 16 anos de idade e 5,3\% tinham sido testemunha ou vítima de abuso sexual.

Um dos motivos pela exiguidade dos estudos que façam a identificação do perfil de vitimizadores sexuais pode ser a dificuldade de interação com os mesmos (visto que a maioria não se propõe a comentar sobre o assunto), além do fato de que, costumeiramente, a população de vitimizadores pesquisados está sob custódia judicial, o que acaba por dificultar o acesso a eles e mesmo a confiabilidade das informações prestadas (Castillo \& Rangel-Noriega, 2013; Vieira, Grossi \& Gasparotto, 2014). Outra situação que dificulta a análise de características dos vitimizadores é a variada forma de atuação nas relações abusivas e, também, na interação com a vítima, especialmente considerando se o abuso é intra ou extrafamiliar (Costa et al., 2018; Santos et al., 2015; Seto et al., 2015). No 
primeiro caso, estes atos podem ocorrer, principalmente, em ambiente doméstico, sendo praticados, na maioria das vezes, por um parente próximo. No contexto extrafamiliar, a agressão sexual ocorre, com maior frequência, fora da residência das vítimas (Costa et al., 2018).

De acordo com a meta-análise de Seto et al. (2015), o vitimizador extrafamiliar tende a possuir orientação homossexual ou bissexual, diferentemente dos intrafamiliares, que tendem a ser heterossexuais. Entretanto, o estudo de Smallbone e Worttley (2001) concluiu que os vitimizadores extrafamiliares e os mixed (intra e extrafamiliares) apresentaram maior tendência a revelar essas orientações sexuais (homossexualidade e bissexualidade) do que os intrafamiliares, ainda que a maioria fosse heterossexual. Os resultados do estudo de Santos e Ippolito (2011) corroboram com a pesquisa descritiva de levantamento documental realizada no ano de 2014 por Hohendorff, Costa, Habigzang e Koller (2014), a qual objetivou investigar as formas de agressão sexual contra meninos. Neste estudo, os autores analisaram 239 fichas de notificação de violência sexual da Coordenadoria Geral de Vigilância em Saúde da cidade de Porto Alegre/RS e concluíram que a violência ocorreu com mais frequência no contexto intrafamiliar $(57,9 \%)$, sendo a residência das vítimas, o local mais frequente das ocorrências $(78,7 \%)$, enquanto que, no contexto extrafamiliar, foram citados espaços coletivos, como unidades de cuidado institucional $(6,5 \%)$, via pública $(5,7 \%)$ e escolas $(5,2 \%)$. Os vitimizadores, maioria do sexo masculino (93\%), se identificaram com orientação heterossexual.

O estudo de Jesus e Moreira (2015) ressaltou que, no contexto intrafamiliar, a maior parte dos supostos autores de agressão sexual de crianças e adolescentes, além de possuírem relacionamentos conjugais e filhos, também estavam empregados e desempenhavam atividades profissionais diversificadas. Em acréscimo, Taveira, Frazão, Dias, Matos e Magalhães (2009) realizaram um estudo, com base na análise dos relatórios médico-legais da Delegação do Norte do Instituto Nacional de Medicina Legal de Portugal, relativos a supostos abusos sexuais em crianças e adolescentes, menores de 18 anos $(\mathrm{N}=764)$, referenciando 67\% do total dos casos de crimes sexuais observados. Os resultados revelam que 34,9\% das agressões eram de cunho intrafamiliar e que existem diferenças significativas em relação ao contexto extrafamiliar, pois, nos crimes intrafamiliares, as vítimas são mais jovens, os indivíduos apresentam mais agressões sexuais anteriores, práticas sexuais menos intrusivas fisicamente, mais violência psicológica na interação, intervalo de tempo maior entre o último episódio abusivo e o exame médico-legal e, também, menos violência física. Pesquisas ainda revelam que a agressão sexual intrafamiliar tem sido associada à presença de atos com características duradouras e frequentes, cujos efeitos psicológicos podem ser ainda mais preocupantes nessas circunstâncias, visto que incluem o sentimento de culpa por parte das vítimas, justamente por se tratar de relacionamentos baseados em laços afetivos (Hamby, Finkelhor \& Turner, 2013; Pincolini \& Hutz, 2014).

Em relação ao perfil dos vitimizadores sexuais infantis, algumas pesquisas abordaram dados de notificação, como o estudo de Platt et al. (2018), o qual descreveu dados do Sistema de Informação de Agravos de Notificação (SINAN). As autoras analisaram todos os casos de suspeita ou confirmação de abuso sexual infantil, no período de janeiro de 2008 a dezembro de 2014 , notificados por um hospital pediátrico da cidade 
de Florianópolis/SC. As características dos autores de agressão sexual registrados revelam que $66,5 \%$ eram conhecidos das vítimas, predominantemente do sexo masculino $(91,9 \%)$, não haviam consumido álcool antes e durante a situação abusiva $(68,6 \%)$ e atuaram sozinhos $(85,2 \%)$.

Em relação à escolaridade, Valencia, Labrador e Peña (2010) analisaram dados sociodemográficos de 43 homens condenados por crimes sexuais contra crianças e adolescentes na Espanha. Os resultados apontaram que os indivíduos que apresentaram fracasso escolar cometeram o primeiro delito entre 12 e 39 anos de idade, diferentemente dos que frequentaram a escola, que tiveram sua primeira experiência delitiva entre 20 e 41 anos. Os pesquisadores afirmam que o fracasso escolar, assim como evasão e o baixo rendimento acadêmico, está presente em um número alto de agressores sexuais. Em contrapartida, o estudo de Costa et al. (2018), por meio de consulta a 206 processos de uma vara especializada em crimes contra a criança e o adolescente, entre os anos de 2012 e 2014, em Belém/PA, revelou que a escolaridade dos acusados de agressão, no contexto intrafamiliar, foi baixa (dos anos iniciais até o ensino fundamental completo $-44 \%$ dos casos), mas, no contexto extrafamiliar, a prevalência foi de alta escolaridade (do ensino médio incompleto até o ensino superior $-42 \%$ dos casos).

Partindo desse panorama, o presente estudo se propõe a descrever o perfil sociodemográfico, judicial e as experiências na família de origem de homens condenados pelo crime de estupro de vulnerável contra crianças e adolescentes. A análise do perfil de vitimizadores sexuais é essencial para o planejamento de intervenções psicológicas destinadas a essa população, uma vez que somente o cumprimento de pena não garante a diminuição das chances de reincidência (Baltieri, 2013). Mais especificamente, o estudo visa descrever os dados pessoais dos participantes (idade, escolaridade, profissão, renda, estado civil e filhos), apontar as condenações mais frequentes (além do estupro de vulnerável), bem como verificar dados a respeito de possíveis internações psiquiátricas, uso de medicação, diagnóstico para o transtorno pedofílico e comorbidades. Além disso, o estudo também objetivou verificar a possível existência de violência na família de origem dos participantes e comparar as características de condenados por agressão sexual intra e extrafamiliar.

\section{Método}

Trata-se de um estudo transversal descritivo. Também foi realizado um levantamento documental dos processos judiciais dos participantes, a fim de obter dados complementares ao dos questionários aplicados.

\section{Participantes}

A amostra foi composta por 49 homens, com condenação pelo crime de estupro de vulnerável (217-A, CP), com acusação por crimes intra e/ou extrafamiliar e que, estavam sob custódia judicial, cumprindo pena em regime fechado, em um presidio da cidade industrial do município de Curitiba/PR. A partir da definição do local de coleta, por conveniência, todos os homens em cumprimento de pena pelo crime de esupro de vulnerável foram convidados a participar do estudo. 


\section{Instrumentos}

Foi elaborada uma ficha para a caracterização dos participantes. Este instrumento continha questões sobre idade, renda mensal, escolaridade, profissão, estado civil do participante e se possui filhos, além de informações a respeito do crime e de sua condição judicial e, também, informações sobre internações psiquiátricas, dependência química, diagnóstico e tratamento para transtornos mentais.

Também foi realizada a aplicação do Family Background Questionnaire - FBQ (Melchert, 1998), o qual apresenta-se como um instrumento autoaplicável, composto por 179 questões, com respostas no formato Likert, de cinco pontos. As questões compõem 22 subescalas que tratam sobre as recordações do indivíduo acerca das experiências vividas em sua família de origem. Ressalta-se que a escala é voltada para adultos e objetiva investigar as memórias de experiências na família de origem dos participantes, até os 18 anos de idade. Para este estudo, foram aplicadas as subescalas que avaliam a vivência de violência na família de origem, conforme objetivos do estudo, as quais correspondem à negligência física (sete itens), abuso físico materno (dois itens) e paterno (dois itens), violência sexual (cinco itens), abuso de substâncias materno (cinco itens) e paterno (cinco itens), ajustamento psicológico materno (dez itens) e paterno (dez itens) e aliança parental (quinze itens) (Melchert, 1998). Este instrumento apresenta um coeficiente alpha de Cronbach entre .76 e .96 nas diferentes subescalas e .98 na escala total, indicando a adequação para mensuração das referidas dimensões (Melchert, \& Kalemeera, 2009). Traduzido para o português por Falcke (2003), obteve índices de confiabilidade de 99 para a escala total e entre .40 e .95 para as subescalas. Menor alpha foi obtido em escala com poucos itens e que não pressupõe consistência entre os itens, como a subescala de abuso sexual que avalia o abuso sofrido por diferentes pessoas, pois isso sendo considerado aceitável.

\section{Procedimentos de Pesquisa e Éticos}

Foi feito, primeiramente, um contato formal com o local de pesquisa, que se trata de uma penitenciária da cidade industrial do município de Curitiba/PR. Também se contatou com o Departamento Penitenciário do Estado do Paraná (DEPEN), que analisou a solicitação de pesquisa. Após a obtenção da Carta de Anuência para a realização da pesquisa, o projeto foi submetido à avaliação do Comitê de Ética da Universidade do Vale do Rio dos Sinos (protocolo 2.662.961). Para a realização desta pesquisa, o responsável pela instituição assinou o Termo de Cessão de Informações, autorizando a utilização dos dados dos processos judiciais para fins da pesquisa, assim como a pesquisadora também se comprometeu em utilizar as informações de forma segura e ética, não divulgando dados que possam comprometer e/ou identificar os participantes. Os sujeitos foram convidados a responder a pesquisa de forma voluntária, respeitando o critério de inclusão de estarem cumprindo pena em regime fechado pelo crime de estupro de vulnerável contra crianças e adolescentes. Os indivíduos que não se disponibilizaram a participar, desistiram ou que estavam de alguma forma impedidos por questões judiciais (3) foram excluídos da amostra, visando gerar o menor prejuízo psicológico possível. Os participantes assinaram o Termo de Consentimento Livre e Esclarecido e todos os seus direitos foram 
respeitados, no sentido de preservação de sua identidade, garantia do direito de não responder alguma questão ou interromper sua participação em qualquer momento. Os participantes que se mobilizaram ao responderem as questões foram acolhidos e um optou por desistir de colaborar com o estudo. A coleta foi realizada na própria instituição penitenciária pela primeira autora deste artigo, com um grupo de estagiarias de psicologia devidamente treinadas. Os instrumentos foram aplicados por um período médio de 50 minutos em pequenos grupos para que cada participante estivesse na presença de uma pesquisadora, disponível para solucionar dúvidas no preenchimento ou ler as questões, quando necessário.

\section{Análise dos Dados}

A análise dos dados ocorreu através do programa Statistical Package for Social Science (SPSS), versão 22.0. Foram realizadas análises descritivas (frequência, média, desvio padrão e porcentagens), além dos testes não paramétricos de Mann-Whitney e Kruskal-Wallis para comparação entre vitimizadores intra e extrafamiliar, considerando que os dados não cumpriram requisitos de normalidade.

\section{Resultados}

A análise do perfil sociodemográfico dos participantes foi elaborada a partir de uma ficha, a qual contém dados pessoais e informações sobre a condenação, assim como com base em dados disponíveis nos processos judiciais. Dos 49 homens que compuseram a amostra, a média de idade foi de 42,96 anos $(\mathrm{DP}=10,6)$. $\mathrm{O}$ tempo de relacionamento conjugal, considerando os participantes casados $(\mathrm{n}=18)$, variou de um a 39 anos $(\mathrm{M}=$ $16,52 ; \mathrm{DP}=12,7)$. A quantidade de filhos dos participantes da amostra que possuíam $(\mathrm{n}=37)$, variou de um a seis, com média de $2,40(\mathrm{DP}=1,4)$, enquanto que o número de enteados dos que possuíam ( $\mathrm{n}=12$ ) variou de um a quatro, com média de $2,50(\mathrm{DP}=1,2)$. Ainda no que se refere ao perfil socioeconômico, a renda dos participantes no momento da condenação pelo crime de estupro de vulnerável (217-A, CP) variou de $\mathrm{R} \$ 900,00$ a $\mathrm{R} \$ 20.000,00$, com média de $\mathrm{R} \$ 3.100,42(\mathrm{DP}=3752,7)$. Outras características que descrevem o perfil dos participantes encontram-se na Tabela 1:

Tabela 1

Perfil sociodemográfico e clínico

\begin{tabular}{llcc}
\hline & & Frequência (n) & Porcentagem válida \\
\hline \multirow{3}{*}{ Escolaridade } & Fundamental incompleto & 16 & 34,0 \\
& Fundamental completo & 14 & 29,8 \\
& Médio incompleto & 2 & 4,3 \\
& Médio completo & 12 & 25,5 \\
& Superior incompleto & 3 & 6,4 \\
& Superior completo & 1 & 2,1 \\
\hline \multirow{2}{*}{ Estado Civil } & Solteiro & 26 & 53,1 \\
& Casado & 18 & 36,7 \\
& Divorciado & 5 & 10,2 \\
\hline
\end{tabular}




\begin{tabular}{|c|c|c|c|}
\hline & & Frequência (n) & Porcentagem válida \\
\hline \multirow{2}{*}{ Filhos } & $\operatorname{Sim}$ & 37 & 82,2 \\
\hline & Não & 8 & 17,8 \\
\hline \multirow{4}{*}{$\begin{array}{l}\text { Idade dos } \\
\text { Filhos }\end{array}$} & $0-10$ anos & 9 & 27,3 \\
\hline & $11-20$ anos & 7 & 21,2 \\
\hline & Acima de 21 anos & 4 & 12,1 \\
\hline & Filhos em diferentes faixas etárias & 13 & 39,4 \\
\hline \multirow{2}{*}{ Enteados } & $\operatorname{Sim}$ & 14 & 45,2 \\
\hline & Não & 17 & 54,8 \\
\hline \multirow{4}{*}{ Idade dos Enteados } & $0-10$ anos & 1 & 8,3 \\
\hline & 11-20 anos & 2 & 16,7 \\
\hline & Acima de 21 anos & 3 & 25,0 \\
\hline & $\begin{array}{l}\text { Enteados em diferentes falxas } \\
\text { etárias }\end{array}$ & 6 & 50,0 \\
\hline Diagnóstico transtorno & $\operatorname{Sim}$ & 3 & 6,1 \\
\hline Pedofílico & Não & 46 & 93,9 \\
\hline \multirow{2}{*}{$\begin{array}{l}\text { Diagnósticos } \\
\text { psiquiátricos }\end{array}$} & $\operatorname{Sim}$ & 3 & 6,5 \\
\hline & Não & 43 & 93,5 \\
\hline \multirow{2}{*}{ Medicação psiquiátrica } & Sim & 5 & 10,6 \\
\hline & Não & 42 & 89,4 \\
\hline \multirow{2}{*}{$\begin{array}{l}\text { Histórico internação } \\
\text { psiquiátrica }\end{array}$} & Sim & 1 & 2,1 \\
\hline & Não & 46 & 97,9 \\
\hline \multirow{2}{*}{$\begin{array}{l}\text { Dependência álcool/ } \\
\text { drogas }\end{array}$} & $\operatorname{Sim}$ & 5 & 45,2 \\
\hline & Não & 41 & 54,8 \\
\hline \multirow{3}{*}{ Quais drogas } & Álcool & 4 & 57,2 \\
\hline & Crack/álcool & 2 & 28,6 \\
\hline & Maconha/crack & 1 & 14,3 \\
\hline \multirow{2}{*}{ Doenças crônicas } & Sim & 6 & 14,0 \\
\hline & Não & 37 & 86,0 \\
\hline
\end{tabular}

No que diz respeito ao perfil judicial, em relação à sentença, foi analisado nos prontuários judiciais o tempo de condenação, não considerando a progressão de regime na execução penal. Os participantes receberam sentenças que variaram de quatro a 220 anos $(\mathrm{M}=27,1 ; \mathrm{DP}=33,3)$. O número de vítimas variou de uma a 15 crianças e/ou adolescentes $(\mathrm{M}=2,54 ; \mathrm{DP}=3,2)$. Em relação às visitas recebidas na penitenciária, $87 \%$ dos participantes indicaram recebe-las. A frequência variou de uma a 15 visitas mensais $(M=5,83 ; D P=5,7)$. As pessoas que visitam foram: irmãos $(n=17)$; mãe $(n=15)$, esposa/ namorada $(n=13)$, filhos $(n=8)$, tia $(n=1)$, sobrinhos $(n=2)$, sogra $(n=1)$, cunhado $(n=1)$ e amigos $(n=1)$. O número total supera o de participantes que recebem visitas, pois alguns recebem mais de uma visita. A tabela 2 apresenta informações judiciais obtidas por meio do questionário sociodemográfico e dos prontuários judiciais. 
Tabela 2

Perfil judicial

\begin{tabular}{|c|c|c|c|}
\hline & & Frequência (n) & Porcentagem válida \\
\hline \multirow{8}{*}{ Ano do crime } & 2009 & 5 & 10,9 \\
\hline & 2010 & 5 & 10,9 \\
\hline & 2011 & 3 & 6,5 \\
\hline & 2012 & 10 & 21,7 \\
\hline & 2013 & 11 & 23,9 \\
\hline & 2014 & 6 & 13 \\
\hline & 2015 & 3 & 6,5 \\
\hline & 2016 & 3 & 6,5 \\
\hline \multirow{3}{*}{ Sexo das vítimas } & Feminino & 26 & 74,3 \\
\hline & Masculino & 7 & 20,0 \\
\hline & Ambos & 2 & 5,7 \\
\hline \multirow{4}{*}{ Idade das vitimas } & 0 a 5 anos & 3 & 8,3 \\
\hline & 6 a 11 anos & 11 & 30,6 \\
\hline & 12 a 18 anos & 12 & 33,3 \\
\hline & Vítimas de diferentes faixas etárias & 10 & 27,7 \\
\hline \multirow{4}{*}{ Método } & Conjunção carnal & 13 & 38,2 \\
\hline & Atos libidinosos & 9 & 26,5 \\
\hline & Sexo oral & 3 & 8,8 \\
\hline & Vários métodos & 9 & 26,5 \\
\hline \multirow{3}{*}{$\begin{array}{l}\text { Crime Intra/ } \\
\text { Extrafamiliar }\end{array}$} & Intrafamiliar & 24 & 54,5 \\
\hline & Extrafamiliar & 17 & 38,6 \\
\hline & Intra e extrafamiliar & 3 & 6,8 \\
\hline \multirow{2}{*}{ Vitima conhecida } & Sim & 36 & 80,0 \\
\hline & Não & 9 & 20,0 \\
\hline \multirow{2}{*}{ Réu confesso } & Sim & 13 & 27,7 \\
\hline & Não & 34 & 72,3 \\
\hline \multirow{2}{*}{ Reincidência } & Sim & 3 & 6,3 \\
\hline & Não & 45 & 93,8 \\
\hline \multirow{2}{*}{$\begin{array}{l}\text { Condenado por } \\
\text { outro crime }\end{array}$} & Sim & 10 & 20,8 \\
\hline & Não & 38 & 79,2 \\
\hline \multirow{10}{*}{$\begin{array}{l}\text { Outros crimes } \\
\text { (Código Penal } \\
\text { Brasileiro e } \\
\text { Estatuto da Criança } \\
\text { e do Adolescente) }\end{array}$} & Art. 14 - Tentativa de homicídio & 1 & 4,3 \\
\hline & Art. 147 - Ameaça & 2 & 8,7 \\
\hline & Art. 157 - Roubo & 1 & 4,3 \\
\hline & Art. 158 - Extorsão & 1 & 4,3 \\
\hline & Art. 171 - Estelionato & 1 & 4,3 \\
\hline & Art. 213a - Estupro & 2 & 8,7 \\
\hline & Art. $218 \mathrm{a}$ - Corrupção de menores & 1 & 4,3 \\
\hline & Art. 240 - Adultério (revogado) & 1 & 4,3 \\
\hline & Art. 241b- Pornografia infantil & 2 & 8,7 \\
\hline & Vários outros crimes & 11 & 47,8 \\
\hline \multirow{2}{*}{$\begin{array}{l}\text { Faltas disciplinares } \\
\text { na prisão }\end{array}$} & Sim & 2 & 4,8 \\
\hline & Não & 40 & 95,2 \\
\hline \multirow{2}{*}{$\begin{array}{l}\text { Tipo de falta } \\
\text { disciplinar }\end{array}$} & Levou tóxico para a galeria & 1 & 50,0 \\
\hline & Tentativa de fuga & 1 & 50,0 \\
\hline
\end{tabular}


Os dados sobre as experiências na família de origem, no que diz respeito à negligência, revelam que $12,2 \%$ dos participantes consideram que os pais ou cuidadores geralmente não verificavam se eles tinham comida e $10,2 \%$ geralmente não monitoravam as roupas que vestiam na infância. Em casos mais graves, $6,1 \%$ revelam que o pai não confortava nem quando estavam doentes e $2,0 \%$ que a mãe também não tinha essa atitude.

Considerando o abuso físico parental, $20 \%$ dos participantes revelam que os pais (tanto o pai como a mãe) foram violentos fisicamente com eles mais de 20 vezes ao longo da infância. Além desses, $28,9 \%$ dos participantes revelaram pelo menos um episódio de violência física cometida pelo pai e $23 \%$ pelo menos um episódio de violência física materna.

O abuso sexual paterno foi sofrido por $2,2 \%(\mathrm{n}=1)$ dos participantes, enquanto que $6,1 \%$ foram abusados sexualmente pela mãe $(\mathrm{n}=3)$. Além disso, $20,4 \%$ foram abusados sexualmente por parentes mais velhos e $8,5 \%$ por outras pessoas (vizinhos, namorados, babás, professores ou estranhos) com uso de força física. Por fim, 20,4\% relataram que sofreram contato sexual indesejado, sem uso da força física. A frequência do abuso variou entre 1 e 12 episódios, mas cinco participantes indicaram que foram "vários", "muitos", "alguns" episódios ou "não sei precisar". A idade do primeiro episódio de abuso sexual variou entre 4 e 18 anos e do último episódio variou entre 10 e 49 anos.

Considerando a avaliação das figuras parentais, o pai foi considerado dependente químico por $33,3 \%$ dos participantes, enquanto que $10,7 \%$ indicaram a mãe como dependente química. Além disso, $17,7 \%$ dos participantes indicaram que o pai tinha problema mental ou emocional e $14,6 \%$ a mãe. Avaliando a violência interparental, constata-se que $48,8 \%$ dos participantes indicaram que o pai ameaçou bater na mãe pelo menos uma vez e que $43,9 \%$ efetivamente a agrediu. Por outro lado, $31 \%$ indicaram que a mãe ameaçou bater no pai e 14,3\% efetivamente agrediu.

$\mathrm{Na}$ comparação das características entre vitimizadores intra e extrafamiliar, por meio dos testes de Mann-Whitney e Kruskal-Wallis, não foram constatadas diferenças significativas $(\mathrm{p}>0,05)$ no que se refere à idade, à renda, ao estado civil, ao tempo de relacionamento conjugal, à existência ou não de filhos, ao número de filhos, à idade das vítimas e nem ao método utilizado. A única diferença encontrada foi em relação à experiência de negligência na família de origem $(\mathrm{U}=1682,5 ; \mathrm{p}=0,024 ; d=0,36)$, em que os vitimizadores de contextos extrafamiliares apresentaram maiores níveis de negligência $(\mathrm{M}=22,71)$ do que os de intrafamiliares $(\mathrm{M}=14,66)$.

\section{Discussão}

Na descrição dos vitimizadores sexuais, constata-se que 63,8\% dos indivíduos apresentaram ensino fundamental completo ou incompleto, corroborando com os resultados do estudo de Valencia, Labrador e Peña (2010) sobre a preponderância de baixa escolaridade. Dado que demanda atenção tanto no que se refere aos instrumentos de avaliação, que precisam ser de fácil compreensão, como ao planejamento de intervenção em linguagem acessível. 
Em relação ao estado civil, a maioria dos indivíduos $(53,1 \%)$ se identifica como solteiro, novamente se relacionando com o estudo de Valencia, Labrador e Peña (2010), que aponta que agressores solteiros e separados/divorciados são maiores em número em relação aos casados e cometeram mais crimes sexuais. Já a pesquisa de Costa et al. (2018) revelou que, dos 96 acusados por crimes sexuais no contexto intrafamiliar, 76\% possuíam cônjuge, diferentemente do encontrado no contexto extrafamiliar $(\mathrm{N}=110)$, em que $54 \%$ não apresentavam essa condição. Ainda em relação à situação conjugal, pode-se analisar que, mesmo que a amostra se apresente em sua maioria como solteira $(53,1 \%)$, os casados $(36,7 \%)$ revelaram relacionamentos longínquos, variando de um a 39 anos. Além disso, a maioria dos participantes indicou a existência de filhos $(82,2 \%)$ e de enteados $(45,2 \%)$. Este dado corrobora com achados da literatura, a qual confirma que a maioria dos vitimizadores sexuais infantis constituem família em algum momento da vida (Scortegagna \& Amparo, 2013; Seto et al., 2015). Esse dado demanda atenção para a preponderância de um perfil não exclusivo, quando, além das crianças e/ou adolescentes, o indivíduo também se sente atraído por adultos (American Psyachiatric Association [APA], 2017).

Outro dado a ser analisado é que somente 6,1\% da amostra possuía (através dos prontuários judiciais) o diagnóstico de transtorno pedofílico (APA, 2017), dado que corrobora com o estudo de Baltieri (2013), quando o autor afirma que o número de homens que sofrem condenação por crimes sexuais contra crianças e/ou adolescentes sem diagnóstico de transtorno pedofílico é muito superior em relação aos que apresentam. $\mathrm{O}$ autor ainda comenta que cerca de $20 \%$ dos indivíduos condenados por estupro de vulnerável podem apresentar características que atinjam os critérios diagnósticos para o transtorno pedofílico, ainda que não tenham sido diagnosticados. Uma boa avaliação relacionada a presença ou não de transtorno pedofílico seria essencial para o planejamento de intervenções adequadas com essa população, concomitante ao cumprimento da pena, para evitar a reincidência após a reinserção social.

Em relação à condenação, observa-se que o crime ocorreu majoritariamente (74,3\%) contra crianças e/ou adolescentes do sexo feminino. Quanto às idades das vítimas, 33,3\% foram identificadas com idades que variavam de 12 a 18 anos de idade, não revelando grande diferença em relação às vítimas de 6 a 11 anos de idade $(30,6 \%)$. O recente estudo de Platt et al. (2018) aponta que a faixa etária mais acometida no sexo feminino foi a de 10 a 15 anos (41,2\%); no masculino, de 2 a 6 anos (42,5\%). A literatura destaca, como também encontrado no presente estudo, as meninas como principais vítimas de violência sexual (Gawryszewski, Valencich, Carnevalle, \& Marcopito, 2012; Platt et al., 2018; Santos et al., 2015) e discorre que este dado ocorre, possivelmente, em decorrência do preconceito que surge quanto à identidade sexual após o abuso de meninos, além de questões relacionadas à desigualdade de gênero (Hamby et al., 2013).

Ainda em relação ao crime de estupro de vulnerável, o método utilizado com maior frequência foi à conjunção carnal $(38,2 \%)$, o que pode ser considerado esperado no contexto de vitimizadores em cumprimento de pena, destacando que este método se apresenta como o de maior facilidade de detecção e obtenção de provas materiais por avaliação médica. Quanto à autoculpabilização, mesmo que a maioria dos processos tenha descrito a conjunção carnal como o principal método, somente $27,7 \%$ da amostra 
se revelou réu confesso. Este dado pode revelar múltiplas interpretações, desde o fato da prova material produzida não se apresentar como definitiva quanto à autoria da conjunção carnal, ou então o fato de que, mesmo diante da prova material conclusiva, os vitimizadores optem por não confessar o ato (razões subjetivas para esta escolha), revelando-se como vítimas de vingança, de um equívoco no reconhecimento, entre outras alegações que eles fizeram questão de registrar no questionário.

A amostra relevou que as experiências de condenação pelo estupro de vulnerável ocorreram, preponderantemente, em contexto intrafamiliar $(54,5 \%)$, seguido por extrafamiliar $(38,6 \%)$ e por contextos mistos, tanto intrafamiliares quanto extrafamiliares (6,8\%), corroborando os estudos de Hohendorff et al. (2014) e Jesus e Moreira (2015), os quais revelaram índices superiores em relação à vitimização sexual de crianças e/ou adolescentes no contexto intrafamiliar. Em contrapartida, a pesquisa de Baía, Veloso, Habigzang, Dell'Aglio e Magalhães (2015), que comparou os padrões de revelação e descoberta de abuso sexual entre os estados do Rio Grande do Sul e do Pará, apontou que o primeiro estado destacou as ocorrências de agressão sexual no contexto intrafamiliar $(62,41 \%)$ em maior número, em relação ao contexto extrafamiliar, enquanto que no segundo estado predominaram ocorrências no contexto extrafamiliar (67,7\%) em número superior. Ainda nesta perspectiva, o recente estudo de Costa, Rocha e Cavalcante (2018) revelou que dos 206 processos pesquisados, em 99 (48,1\%), os acusados da agressão sexual pertenciam ao contexto intrafamiliar e, em 107 (51,9\%), ao contexto extrafamiliar. A literatura revela discrepância de achados conforme o contexto amostral, o que amplia a necessidade de atenção aos diferentes perfis de vitimizadores, considerando as idiossincrasias da violência cometida dentro e fora da família, destacando-se que neste estudo, em relação ao perfil sociodemográfico e judicial não houve diferenças entre vitimizadores intra e extrafamiliar.

Em relação às visitas recebidas durante o encarceramento, verifica-se que a maioria dos participantes da amostra $(87 \%)$ recebe visitas mensais, sendo que as pessoas que mais visitam foram: irmãos $(n=17)$; mãe $(n=15)$, esposa/namorada $(n=13)$ e filhos $(n=8)$. São escassos os estudos que analisam as visitas recebidas por condenados de crimes sexuais contra crianças e/ou adolescentes dentro da instituição prisional (Marafiga et al., 2017). Entretanto, Sanfelice e De Antoni (2010) consideram que receber visitas no sistema prisional é um fator de relevância social, uma vez que o apenado que não possui visitas é tido como abandonado, possuindo menores chances de ressocialização.

Dentre os dados sobre as experiências vivenciadas na família de origem, destacamse os resultados sobre abusos sexuais vividos na infância e adolescência, considerando que o instrumento aplicado (FBQ), o qual verifica as experiências na família de origem, questiona não só situações vividas pelo participante e seus familiares, como também, experiências de violência por parte de outras pessoas. Foram relatados abusos sexuais pelo pai $(n=1)$ e pela mãe $(n=3)$, além de $20,4 \%$ declararem terem sido vitimizados sexualmente por parentes mais velhos e $8,5 \%$ por outras pessoas (vizinhos, namorados, babás, professores ou estranhos) com uso de força física. Em acréscimo, 20,4\% da amostra revela ter vivido experiências de contatos sexuais indesejados, sem uso da força física, tendo o primeiro contato sexual entre 4 e 18 anos de idade, e o último episódio, dos 10 aos 49 anos. Este dado representa um fator de extrema relevância, justamente por 
apresentar uma porcentagem alta para verificação de situações de agressão sexual na vida pregressa de vitimizadores sexuais de crianças e adolescentes e acaba se relacionando com diversos estudos prévios (Baltieri, 2013; Nascimento, 2017). Nakatani (2012) ressalta que os indivíduos que foram sexualmente vitimizados quando criança e/ou adolescentes podem repetir o mesmo padrão ao qual foram submetidos, por não terem percebido o seu sofrimento de forma clara, podendo até repetir o ciclo de vitimização. Outro dado que chama atenção em relação às experiências de contatos sexuais indesejados, seria a idade de 49 anos revelada pela amostra como de ocorrência do último episódio. Este dado pode ser compatível com as experiências de vitimização que homens condenados por crimes sexuais sofrem inclusive dentro do ambiente prisional (Veloso \& Ribeiro Junior, 2018). Destaca-se na compreensão deste dado que se precisa considerar não somente as experiências descritas pelos vitimizadores como abuso sexual propriamente dito, como também a iniciação sexual precoce, ainda na infância, que caracterizaria violência sexual, mas eles, por distorções cognitivas, muitas vezes não avaliam como tal, naturalizando o contato sexual entre adultos e crianças/adolescentes (Marafiga et al., 2017).

A experiência de agressão sexual na infância de vitimizadores sexuais infantis foi citada por Baltieri (2013) como uma das situações que influenciariam no desenvolvimento de comportamentos sexuais inapropriados na vida adulta. Semelhante a isto, o estudo de Gidycz, Warkentin e Orchowski (2007) ressaltou que 18\% da amostra de agressores sexuais infantis revelaram terem sofrido alguma forma de agressão sexual em sua vida pregressa, e $84 \%$ dos participantes destacaram vitimização física e maus tratos verbais severos na infância. O estudo de Valencia, Labrador e Peña (2010), ao analisar a história de vitimizadores sexuais constatou que infratores com histórico de abuso sexual na infância cometeram em média sete crimes sexuais, em comparação com o outro grupo (sem história abusiva na vida pregressa) que cometeram, em média, três crimes sexuais contra crianças e/ou adolescentes.

Além dessas, as experiências de negligência, violência intrafamiliar e carência de supervisão parental também foram citadas como preditoras de atos abusivos no futuro (Titcomb et al., 2012). Os participantes ressaltaram negligência em diversos aspectos, como a falta de verificação de comida $(12,2 \%)$, de vestimentas $(10,2 \%)$ e, em casos mais graves, que os pais $(6,1 \%)$ e mães $(2,0 \%)$ não confortavam nem quando estavam doentes. A negligência se revela como outro preditor da existência de comportamentos sexuais violentos contra crianças e adolescentes. Este dado pode ser verificado em diversos estudos (Baltieri, 2013; Marafiga et al., 2017). Neste estudo, os resultados revelaram que os vitimizadores de contextos extrafamiliares apresentaram maiores níveis de negligência na família de origem $(m=22,71)$ do que os intrafamiliares $(m=14,66)$. De acordo Henriques (2016), rejeição, abandono e desconfiança acarretam desajustamento emocional do indivíduo e, em contrapartida, segurança, respeito, vinculação, intimidade e aceitação proporcionam satisfação. Contudo, segundo a autora, a maioria dos agressores sexuais apresentam famílias emocionalmente distantes e negligentes.

O estudo também revelou a existência de figuras paternas instáveis, sendo que $33,3 \%$ dos participantes consideram o pai dependente químico e 10,7\% a mãe. Do total, $48,8 \%$ dos participantes destacaram que o pai ameaçou bater na mãe pelo menos uma vez e que $43,9 \%$ efetivamente a agrediram. Este dado corrobora com os estudos de Valencia, 
Labrador e Peña (2010) os quais afirmam que os vitimizadores sexuais têm uma alta probabilidade de crescer em famílias em que o apego com suas figuras parentais tenha sido uma experiência destrutiva e que ensine a enfrentar os problemas com violência ou qualquer estratégia justamente para não se preocuparem com os mesmos.

Considerando o abuso físico parental, $20 \%$ dos participantes revelam que tanto o pai como a mãe foram violentos fisicamente com eles mais de 20 vezes ao longo da infância. Segundo Gerardin e Thibaut (2004), os fatores ambientais que explicam a agressão sexual em crianças e adolescentes variam da exposição a padrões de comportamento agressivos, experiências de abuso, exposição à pornografia e abuso de substâncias. Os autores verificaram que $66 \%$ de uma amostra de agressores sexuais infantis sofreram vitimização física (19\%) ou sexual (49\%), replicando a violência sofrida enquanto crianças e/ou adolescentes. Os dados são semelhantes aos obtidos no presente estudo em que se pode destacar que em torno de $10 \%$ dos sujeitos referiram sofrer negligência, $20 \%$ abuso físico parental e 30\% abuso sexual na infância ou adolescência. Ainda que estes índices sejam superiores aos encontrados em estudo com população não clínica (Colossi, Marasca, \& Falcke, 2015), constata-se que a maioria dos participantes não revelou experiências de negligência ou abusos na infância, trazendo à tona a necessidade de melhor compreender as experiências de vitimizadores sexuais sem partir de uma lógica determinista de que todo vitimizador foi vítima de abuso no passado.

\section{Considerações Finais}

A violência sexual contra crianças e adolescentes é considerada um fenômeno complexo, multicausal, que gera significativos prejuízos físicos e psicológicos tanto para as vítimas, quanto para os vitimizadores e para a sociedade em geral. Para tanto, a relevância deste estudo se dá pela possibilidade de ampliar os conhecimentos a respeito do perfil sociodemográfico e criminal de indivíduos condenados pelo crime de estupro de vulnerável, além verificar as experiências na família de origem dos participantes.

É mister salientar como limitação desta pesquisa que, apesar de se tratar de um estudo com base em prontuários judiciais e informações advindas dos indivíduos que compuseram a amostra, nem sempre se obteve esse número $(\mathrm{N}=49)$ nas observações estatísticas, devido à falta de informação nos processos e nas considerações individuais, por conta da voluntariedade e disposição dos participantes.

Ressalta-se a necessidade de novos estudos com enfoques quantitativos e qualitativos, com objetivo de compreender de forma mais aprofundada, dados referentes a indivíduos que apresentam interação sexual com crianças e/ou adolescentes, especialmente focando em suas histórias de vida, relacionamento com a família de origem e existência ou não de relação com o diagnóstico de transtorno pedofílico (APA, 2017). Essas informações são essenciais para o planejamento de intervenções terapêuticas com essa população, visando a sua ressocialização e prevenção de reincidência da vitimização. 


\section{Referências}

American Psyachiatric Association (2017). Manual Diagnóstico e Estatístico de Transtornos Mentais DSM-IV. Porto Alegre: Artmed. APA.

Azevedo, M. B., Alves, M. D. S., \& Tavares, J. R. F. (2018). Abuso Sexual Intrafamiliar em Adolescentes e Suas Reflexões. Psicologia para América Latina, (30), 7-25

Baía, P. A. D., Veloso, M. M. X., Habigzang, L. F., Dell'Aglio, D. D., \& Magalhães, C. M. C. (2015). Padrões de revelação e descoberta do abuso sexual de crianças e adolescentes. Revista de Psicología, 24(1), 1-19.

Baltieri, D. (2013) Pedofilia como transtorno comportamental psiquiátrico crônico e transtornos comportamentais associados. Brasília Médica, 50 (2), 122-131.

Barros, C. A. (2017). Parafilias, Pedofilia e intervenções em Terapia Cognitivo Comportamental. Revista Psique, 2 (3), 78-9.

Bertoli, C., Benato, R. H., \& Machado, P. G. B. (2018). Pedofilia: um estudo teórico sob a ótica na analise do comportamento. Educação e Humanidades, 12 (1), 44-58.

Casarin, J. M., Botelho E. H. L., \& Ribeiro, R. K. S. M. (2016). Ofensores sexuais avaliados pelo Desenho da Figura Humana. Avaliação Psicológica, 15(1), 61-72.

Castillo, R. L., \& Rangel-Noriega, K. J. (2013). Agresor sexual. Aproximación teórica a su caracterización. Informes psicológicos, 13(2), 103-120.

Chan, H. C., Beauregard, E., \& Myers, W.C. (2015). Single-victim and serial sexual homicide offenders: differences in crime, paraphilias and personality traits. Crim Behav Ment Health, 25 (1), 66-78.

Colossi, P. M., Marasca, A. R., \& Falcke, D. (2015). De geração em geração: a violência conjugal e as experiências na família de origem. Psico, 46(4), 493-502.

Cohen, L. J., Ndukwe, N., Siegfried, R., Kopeykina, I., Yaseen, Z. S., \& Galynker, I. (2018). Attraction Versus Action in Pedophilic Desire: The Role of Personality Traits and Childhood Experience. Journal of Psychiatric Practice ${ }^{\circledR}, 24(6), 374-387$.

Costa, L. P., Rocha, C. J. B., \& Cavalcante, L. I. C., (2018). Características Biopsicossociais entre Acusados de Agressão Sexual contra Crianças/Adolescentes em Contextos Intra e Extrafamiliar. Temas em Psicologia, 26(1), 283-295.

Dyshniku, F., Murray, E. M., Fazio, R. L., Lykins, A. D., \& Cantor, J. M. (2015). Minor Physical Anomalies as a Window in to the Prenatal Origins of Pedophilia. Arch Sex Behav, 44(8), 2151-2159.

Falcke, D. (2003). Águas passadas não movem moinhos? As experiências na família de origem como preditoras da qualidade do relacionamento conjugal. Tese de doutorado. Pontifícia Universidade Católica do Rio Grande do Sul.

Falcke, D. (2020). Avaliação psicológica na violência intrafamiliar.In: Hutz. C. et al. (Orgs.) Avaliação Psicológica no Contexto Forense. Porto Alegre: Artmed.

Fazio, R. L., Lykins, A. D., \& Cantor, J. M. (2014). Elevated rates of atypical handedness in paedophilia: Theory and implications. Laterality, 19(6), 690-704.

Gawryszewski, V. P., Valencich, D. M. O., Carnevalle, C. V., \& Marcopito L. F., (2012). Maus-tratos contra a criança e o adolescente no Estado de São Paulo. Revista Assoc. Med. Bras., 58(6), 659-665.

Gerardin, P., \& Thibaut, F. (2004). Epidemiology and Treatment of Juvenil Sexual Offending. Pediatric Drugs, 6 (2), 79-91. 
Gidycz, C., Warkentin, J., \& Orchowski, L. (2007). Predictors of perpetration of verbal, physical and sexual violence. A prospective analysis of college men. Psychology and men masculinity, 8 (2), 79-94.

Hamby, S., Finkelhor, D., \& Turner, H. (2013). Perpetrator and victim gender patterns for 21 forms of youth victimization in the National Survey of Children's Exposure to Violence. Violence and Victims, 28(6), 915-39.

Henriques, D. M. E. (2016). Esquemas precoces mal adaptativos e ajustamento emocional à prisão em agressores sexuais de menores. Dissertação, Universidade Lusófona de Humanidades e Tecnologias, Lisboa.

Hohendorff, J. V., Costa, L. S., Habigzang, L. F., \& Koller, S. H. (2014). Análise documental de casos de violência sexual contra meninos notificados em Porto Alegre. Paidéia, 24 (58), 187-196.

Jesus,A.P.C., \& Moreira, R. B. R.(2015). A violência sexual contra crianças e adolescentes no Brasil: Da proteçãojurídica as políticas públicas. Seminário Internacional de Demandas Sociais e Políticas Públicas na Sociedade Contemporânea. Recuperado em: 08/11/2020 $<$ https://online.unisc.br/acadnet/anais/index.php/sidspp/article/view/13166>.

Marafiga, C. V., Falcke, D., \& Teodoro, M. L. (2017). Pedofilia: história de vida e o retorno para a família por meio de alta progressiva. Revista da SPAGESP, 18 (1), 48-62.

Melchert, T. (1998). Testing the validity of an instrument for assessing family of origin history. Journal of Clinical Psychology, 54(7), 863-875.

Melchert, T. P., \& Kalemeera, A. (2009). A brief version of the Family Background Questionnaire. Measurement and Evaluation in Counseling and Development, 41(4), 210-222.

Nascimento, A. C. G. (2017). Características dos Abusdores Sexuais. (Dissertação de Mestrado em Medicina Legal pela Universidade do Porto, Portugal).

Nakatani, F. M. (2012). Abuso sexual intrafamiliar contra a criança: Entre o Direito e a Psicologia. (Dissertação de Mestrado, Universidade Federal do Paraná, Brasil).

Pincolini,A. M. F., \& Hutz, C. S. (2014).Abusadores Sexuais Adultos eAdolescentes no Sul do Brasil:Pesquisa emDenúnciase Sentenças Judiciais. Temas em Psicologia, 22(2), 301-311.

Platt, V. B., Back, I. C., Hauschild, D. B., \& Guedert, J. M. (2018). Violência sexual contra crianças: autores, vítimas e consequências. Ciência \& Saude Coletiva, 23(4), 1019-1031.

Pournaghash-Tehrani, S., \& Feizabadi, Z. (2009). Predictability of physical and psychological violence by early adverse childhood experiences. Journal of Family Violence. 24(6), 417-422.

Reyes, A. C., Ymas, Y.A., Gonzalez, M.A., \& Sanches, V. G. (2012). Análisis diagnóstico del Trastorno de la Preferencia Sexual (Pedofilia). A propósito de un caso. Cuad Med Forense, 18 (3-4), 127-133.

Sanches, L. C., Araujo, G. de, Ramos, M., Rozin, L., \& Rauli, P. M. F. (2019). Violência sexual infantil no Brasil: uma questão de saúde pública. Revista Iberoamericana de Bioética, (9), 1-13.

Sanfelice, M. M., \& De Antoni, C. (2010). A percepção do abusador sexual sobre a (sua) sexualidade. Interamerican Journal of Psychology, 44(1), 131-139.

Santos, B. R., \& Ippolito, R. (2011). Guia escolar: identificação de sinais de abuso e exploração sexual de crianças e adolescentes. Ministério da Educação/ Secretaria Especial dos 
Direitos Humanos. Seropédica, Rio de Janeiro: EDUR. Disponível em: $<$ http://portal. mec.gov.br/index.php?option=com_docman\&view=download\&alias $=32151$-guiaescolar-rede-de-protecao-pdf\&Itemid $=30192>$.

Santos, C. A., Costa, M. C. O., Amaral, M. T. R., Sobrinho, C. L. N., de Oliveira Musse, J., \& da Costa, A. M. (2015). Agressor sexual de crianças e adolescentes: análise de situações relacionadas à violação e vítimas. Adolescencia e Saude, 12(3), 7-20.

Scortegagna, S. A., \& Amparo, D. A. (2013). Avaliação psicológica de ofensores sexuais com o método de Rorschach. Avaliação Psicológica, 12 (3), 411-419.

Seto, M. C., Babchishin, K. M., Pullman, L. E., \& McPhail, I. V. (2015). The puzzle of intrafamilial child sexual abuse: A meta-analysis comparing intrafamiliar and extrafamilial offenders with child victims. Clinical Psychology Review, 39, 42-57.

Silva, L. O. G., \& Gonçalves, J. P. (2019). Violência sexual praticada contra crianças e adolescentes: perspectivas de pessoas que vivenciaram essa realidade. Revista Cocar, 13(26), 497-519.

Smallbone, S. W., \& Wortley, R. K. (2001). Child sexual abuse: Offender characteristics and modus operandi, No. 193. Canberra: Australian Institute of Criminology Trends and Issues in Crime and Criminal Justice.

Taveira, F., Frazão, S., Dias, R., Matos, E., \& Magalhães, T. (2009). O abuso sexual intra e extrafamiliar. Acta Médica Portuguesa, 22(6), 759-66.

Titcomb, C., Goodman-Delahunty, J., \& Puiseau, B. W. (2012). Pretrial diversion for intrafamilial child sexual offending does biological paternity matter? Criminal Justice and Behavior, 39 (4), 552-570.

Valencia, O. L., Labrador, M. A., \& Peña, M. R. (2010). Características demográficas y psicosociales de los agresores sexuales. Revista Diversitas: Perspectivas en Psicología, 6 (2), 297-308.

Vanderstukken, O., Benbouriche, M., Pham T. H., \& Lefebvre, L. (2015). Les distorsions cognitives des auteurs d'agression sexuelle d'enfant: définitions, fonctions, et enjeux théoriques. Journal de Thérapie Comportementale et Cognitive. 25(1), 29-34.

Veloso, F. M., \& Ribeiro Junior, H. (2018). A legitimação dos linchamentos a partir da narrativa midiática: uma análise da produção discursiva do "bandido" como ser matável. Revista de Estudos Criminais. 17(68), 79-110.

Vieira, M. S., Grossi, P. K., \& Gasparotto, G. P. (2014). A violência sexual infanto-juvenil e o olhar dos profissionais da rede de enfrentamento: Notas críticas acerca do cenário do município de Porto Alegre. Seminário Internacional de Demandas Sociais e Políticas Públicas na Sociedade Contemporânea, (11). Recuperado em: 01 maio de 2020 $<$ http://online.unisc.br/acadnet/anais/index.php/sidspp/article/view/11750/1544>.

Recebido em: janeiro de 2020

Aceito em: abril de 2020

Caroline Velasquez Marafiga: Doutora (Unisinos). Docente do Centro Universitário Curitiba. End. Chile, 1678. Bairro: Rebouças. CEP: 80220-181. Curitiba/PR. +55 41 32138700. carolvmarafiga@hotmail.com Denise Falcke: Doutora. Docente do Programa de Pós Graduação em Psicologia da Unisinos. End. Av. Unisinos, 950. Bairro: Cristo Rei. CEP: 93022-750. São Leopoldo/RS.

E-mail para contato: carolvmarafiga@hotmail.com 